\title{
The Role of Serum Ceruloplasmin and Oxidative Stress Markers in Primary Open Angle Glaucoma
}

\author{
Abdul Monem Al-Sayed Abou Sharkh1, Waled Mahdy Nada1, Doaa Attia Abdel Moety², \\ Hany Ahmad Elkattawy²
}

${ }^{1}$ Ophthalmology Department, Faculty of Medicine, Zagazig University, Zagazig, Egypt

${ }^{2}$ Physiology Department, Faculty of Medicine, Zagazig University, Zagazig, Egypt

Email: walednada_69@hotmail.com

How to cite this paper: Abou Sharkh, A.A., Nada, W.M., Abdel Moety, D.A. and Elkattawy, H.A. (2018) The Role of Serum Ceruloplasmin and Oxidative Stress Markers in Primary Open Angle Glaucoma. Open Journal of Ophthalmology, 8, 18-25. https://doi.org/10.4236/ojoph.2018.81003

Received: December 30, 2017

Accepted: February 2, 2018

Published: February 5, 2018

Copyright (c) 2018 by authors and Scientific Research Publishing Inc. This work is licensed under the Creative Commons Attribution International License (CC BY 4.0).

http://creativecommons.org/licenses/by/4.0/

\begin{abstract}
Purpose: The study aimed at evaluation of the role of ceruloplasmin (A protein involved in iron homeostasis and can inactivate free radicals) and other oxidative stress markers as superoxide dismutase (SOD), malondialdehyde (MDA) and catalase activity (CAT) in primary open angle glaucoma (POAG). Methods: This observational case control study included 90 persons divided into 3 equal groups: group A of 30 normal persons as a control group, group B of 30 patients of untreated (POAG) (firstly diagnosed) by the clinical characters including measuring intraocular pressure (IOP), optic disc cupping and visual field changes and group $\mathrm{C}$ of 30 patients of POAG under medical treatment by topical anti-glaucomatous drugs. Serum ceruloplasmin, superoxide dismutase, malondialdehyde and catalase activity were measured in all groups, statistical analysis of the data was performed. Results: In a comparison to group A of control, serum ceruloplasmin decreased significantly in group B of untreated POAG $(20.95 \pm 6.01) \mathrm{mg}$-dl and in group C of POAG under treatment $(22.15 \pm 6.14) \mathrm{mg}$ - $\mathrm{dl}(\mathrm{P}<0.001)$, and there was no statistically difference between group $\mathrm{B}$ and $\mathrm{C}(\mathrm{P}>0.05)$. Also, serum superoxide dismutase increased significantly in group $B(2.23 \pm 0.4)$ and in group $C$ (2.19 $\pm 0.38) \mathrm{U}-\mathrm{ml}(\mathrm{P}<0.001)$, and there was no statistically difference between group $B$ and $C(P>0.05)$. Serum malondialdehyde increased significantly in group $\mathrm{B}(3.82 \pm 0.74) \mathrm{nmol}-\mathrm{ml}$ and in group $\mathrm{C}(3.55 \pm 0.73) \mathrm{nmol}-\mathrm{ml}(\mathrm{P}<$ $0.001)$ in a comparison to the control group A $(2.23 \pm 0.41) \mathrm{nmol}-\mathrm{ml}$, and there was no statistically difference between group $B$ and $C(P>0.05)$. Serum catalase decreased significantly in group $B(17.97 \pm 2.75) \mathrm{U}-\mathrm{ml}$ and in group $\mathrm{C}$ $(18.75 \pm 2.33) \mathrm{U}-\mathrm{ml}$ in a comparison to the control group $\mathrm{A}(22.67 \pm 3.05)$ U-ml $(\mathrm{P}<0.001)$, and there was no statistically difference between group $B$
\end{abstract}


and $\mathrm{C}(\mathrm{P}>0.05)$. Conclusions: Serum ceruloplasmin level and the antioxidant (CAT) activity significantly decreased, while serum levels of SOD, MDA significantly increased in cases of POAG. This may indicate the need for addition of anti-oxidative stress therapy in combination with the anti-glaucomatous drugs. Monitoring these markers can be considered good indicators for determination of the oxidative stress condition in such cases.

\section{Keywords}

Ceruloplasmin, Primary Open Angle Glaucoma, Oxidative Stress Markers, Superoxide Dismutase (SOD), Malondialdehyde (MDA) and Catalase Activity (CAT)

\section{Introduction}

One of the causes of blindness in many countries is primary open-angle glauco$\mathrm{ma}(\mathrm{POAG})$. It is a progressive disease affecting people above 40 years, optic nerve changes are the main features, intraocular pressure (IOP) is the famous measurable risk factor for POAG, but some cases with the reduction of their IOP either by medical or surgical treatment does not stop the progression of the disease. So, other factors as lack of neurological protection for ganglion cells in the retina and cell apoptosis mechanisms may also play roles in progression of glaucoma [1] [2] [3]. Another factor may be incriminated in the process of POAG such as oxidative stress, other inflammatory factors and characteristic pattern of cell death by apoptosis [4].

Ceruloplasmin is a protein incorporated in iron homeostasis and it is considered to be playing the important role in the inactivation of free radicals. It is also called ferroxidase that utilizes iron oxidase activity to prevent the occurrence of toxic iron products [5] [6]. Also ceruloplasmin reduces the action of superoxide dismutase (SOD) which is an intracellular enzyme of acute phase reactant, scavenges oxygen-derived free radicals [7].

In the course of glaucoma, the inflammatory process, other stress factors and the anti-glaucomatous drugs may increase the permeability of the blood-ocular barrier [8] [9] and may be connected with lower concentration of serum ceruloplasmin in glaucoma patients [10]. Also Erdurmuş et al. (2011) [11] and Rokicki et al. (2016) [12] reported that oxidative stress plays an important role in POAG leading to decreasing antioxidant defense mechanism and increased oxidative stress system in the form of superoxide dismutase and malondialdehyde (MDA). Also one study of Mumcu et al. (2016) [13] agreed to confirm that MDA was increased in patients with POAG, recommending that anti-oxidative therapy must be conjugated with anti-glaucomatous drugs in dealing with POAG patients [14]. Also Awodele et al. (2015) [15] stated that catalase (CAT) activity reduced in serum of patients with POAG as an important oxidative stress marker. 
The present study was limited at evaluating the role of ceruloplasmin and other oxidative stress markers in primary open angle glaucoma before and during medical treatment without studying any other contributing factors that may be incorporated in the pathogenesis of primary open angle glaucoma.

\section{Patients and Methods}

This observational case control study was performed in Ophthalmology Department, Faculty of Medicine, Zagazig University. The study was performed according to WMA Declaration of Helsinki-Ethical Principles for Medical Research Involving Human Subject. A written consent was obtained from all participants. The study included 90 persons who were enrolled consecutively in the study and divided into equal 3 groups, group (A) of 30 persons from $40-65$ years not suffering from POAG or other stress triggering conditions as a control group, group (B) of 30 patients in the same age group and nearly the same conditions as group (A) with untreated POAG, Group (C) of 30 patients with the same criteria as the previous groups with POAG under medical treatment.

The criteria in the control group (A):

- Age from 40 - 65 years.

- Equal males and females ratio.

- Non glaucomatous persons, depending on measuring intraocular pressure by applanation tonometer, optic disc evaluation by fundus examination and normal optic nerve fiber layer thickness by optical coherence topography (OCT Glaucoma Study).

- No degenerative ocular conditions such as cataract or inflammatory conditions.

- Free of systemic diseases such as diabetes or hypertension or systemic degenerative diseases.

Criteria of selection of group (B) and (C):

Nearly, the same criteria in group (A) except they had POAG, firstly diagnosed including group (B), and group (C) who were controlled under medical treatment in the form of topical carbonic anhydrase inhibitor and non-selective B blockers (Dorzolamide-Timolol), the diagnosis of POAG in group B based on the clinical examination by measuring IOP by applanation tonometer more than $24 \mathrm{mmHg}$, optic nerve evaluation by direct fundus examination either normal or increase in cup disc ratio, abnormal visual field test using and abnormal thinning of nerve fiber layer thickness by OCT.

Blood samples were collected from all participants, serum was separated, and the following parameters were measured:

Ceruloplasmin was measured using Ceruloplasmin Activity Colorimetric Assay Kit (K669-BioVision, Inc. USA) sensitivity 5 - 500 mg/dl.

Superoxide dismutase was measured using (SOD) Assay Kit (Cayman Chemicals Item No.706222, 1180 USA), sensitivity from $0.005 \mathrm{U} / \mathrm{ml}$.

Malondialdehyde was measured using Lipid Peroxidation (MDA) Assay Kit (Colorimetric/Fluorometric) (ab118970 ABCAM USA) in nmol/ml. 
Catalase activity was measured using (CAT) Assay Kit (Cayman Chemicals Item No. 707002 USA), sensitivity from $2 \mathrm{U} / \mathrm{ml}$.

Statistical analysis: The data obtained in the present study were expressed as mean SD, and One-Way ANOVA [Posthoc (LSD)] test was used to compare means among more than two groups.

$P$ value $<0.05$ was considered statistically significant.

Corrélation coefficient (r): Pearson's correlation analysis was performed to illustrate the relationships between serum ceruloplasmin and all studied parameters among different groups. Pearson's correlation was considered significant at $P$ values $<0.05$.

\section{Results}

The demographic data of the control group A revealed that the age ranged from 40 - 65 years old with mean age $(51.6 \pm 5.48)$ years, group B of untreated POAG patients revealed range from $42-65$ years with mean age $(53.11 \pm 4.84)$ years and group $\mathrm{C}$ of POAG patients under treatment revealed range from $43-68$ years with mean age $(55.2 \pm 8.08)$ years. Male to female ratio was $1: 1$ in all groups.

Measuring of serum ceruloplasmin in the control group A reported (37.45 \pm $5.55) \mathrm{mg} / \mathrm{dl}$ which decreased significantly in group B of untreated POAG patients $(20.95 \pm 6.01) \mathrm{mg} / \mathrm{dl}(P<0.001)$ and also decreased significantly in group $\mathrm{C}$ of patients of POAG under treatment $(22.15 \pm 6.14) \mathrm{mg} / \mathrm{dl}(P<0.001)$. There was no statistically difference between level of serum ceruloplasmin between group B and C $(P>0.05)$.

Measuring of serum superoxide dismutase in the control group A reported $(0.84 \pm 0.2) \mathrm{U} / \mathrm{ml}$ which increased significantly in group $\mathrm{B}$ of untreated POAG patients $(2.23 \pm 0.43) \mathrm{U} / \mathrm{ml}(P<0.001)$ and also increased significantly in group $\mathrm{C}$ of patients of POAG under treatment $(2.19 \pm 0.38) \mathrm{U} / \mathrm{ml}(P<0.001)$. There was no statistically difference between level of superoxide dismutase between group $\mathrm{B}$ and $\mathrm{C}(P>0.05)$.

Measuring of serum malondialdehyde in the control group A reported $2.23 \pm$ $0.41) \mathrm{nmol} / \mathrm{ml}$ which increased significantly in group B of untreated POAG patients $(3.82 \pm 0.74) \mathrm{nmol} / \mathrm{ml}(P<0.001)$ and also increased significantly in group $\mathrm{C}$ of patients of POAG under treatment $(3.55 \pm 0.73) \mathrm{nmol} / \mathrm{ml}(P<0.001)$. There was no statistically difference between level of malondialdehyde between group $\mathrm{B}$ and $\mathrm{C}(P>0.05)$.

Measuring of serum catalase activity in the control group A reported $(22.67 \pm$ 3.05) $\mathrm{U} / \mathrm{ml}$ which decreased significantly in group B of untreated POAG patients $(17.97 \pm 2.75) \mathrm{U} / \mathrm{ml}(P<0.001)$ and also decreased significantly in group $\mathrm{C}$ of patients of POAG under treatment $(18.75 \pm 2.33) \mathrm{U} / \mathrm{ml}(P<0.001)$. There was no statistically difference between level of catalase activity between group $\mathrm{B}$ and C $(P>0.05)$ (Table 1, Figure 1).

The study reported a negative correlations between serum ceruloplasmin and SOD levels in both group B and group C $\left(\mathrm{r}=0.546^{* *}, P=0.002 \& \mathrm{r}=-0.483^{* *}\right.$, 
Table 1. Serum ceruloplasmin and oxidative stress markers an all groups expressed as (mean $\pm \mathrm{SD})$.

\begin{tabular}{cccc}
\hline Groups & $\begin{array}{c}\text { Group A } \\
\text { (Control) }\end{array}$ & $\begin{array}{c}\text { Group B } \\
\text { (Untreated POAG) }\end{array}$ & $\begin{array}{c}\text { Group C } \\
\text { (POAG under treatment) }\end{array}$ \\
\hline $\begin{array}{c}\text { Serum Ceruloplasmin } \\
(\mathrm{mg} / \mathrm{dl})\end{array}$ & $37.45 \pm 5.55$ & $20.95 \pm 6.01^{* * * a} \mathrm{a}$ & $22.15 \pm 6.14^{* * * a}$ \\
$\begin{array}{c}\text { Serum SOD }(\mathrm{U} / \mathrm{ml}) \\
\text { Serum MDA } \\
(\mathrm{nmol} / \mathrm{ml})\end{array}$ & $0.84 \pm 0.2$ & $2.23 \pm 0.43^{* * * a}$ & $2.19 \pm 0.38^{* * * a}$ \\
Serum CAT $(\mathrm{U} / \mathrm{ml})$ & $2.23 \pm 0.41$ & $3.82 \pm 0.74^{* * * a}$ & $3.55 \pm 0.73^{* * * a}$ \\
\hline
\end{tabular}

$* * *=\mathrm{P}<0.001 ; \mathrm{a}=$ versus group $\mathrm{A}$.

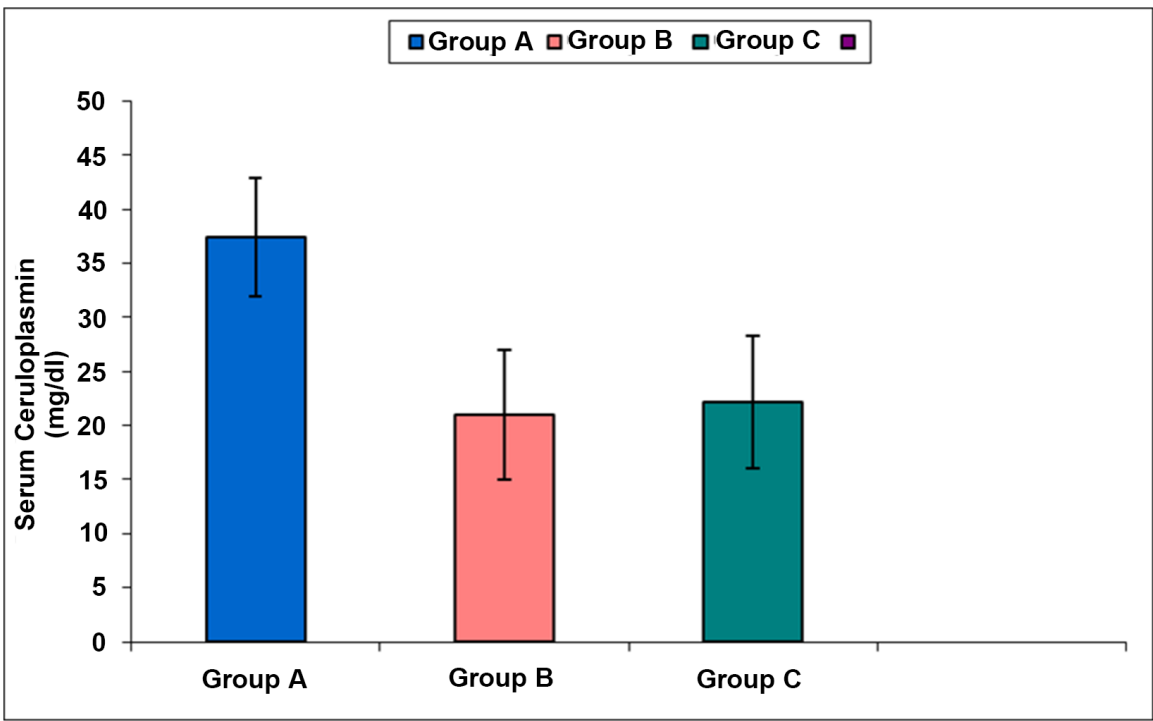

Figure 1. Mean serum ceruloplasmin in all groups.

$P=0.007$ respectively). Also, serum ceruloplasmin level is negatively correlated with serum level of MDA in each of group B and group C $\left(\mathrm{r}=-0.680^{* * *}, P=\right.$ $0.000 \& \mathrm{r}=-0.557^{* *}, P=0.001$ respectively).

On the other hand, positive correlations between serum ceruloplasmin and CAT levels were recorded in both group B and group C $\left(\mathrm{r}=0.596^{* *}, P=0.001 \&\right.$ $\mathrm{r}=0.796^{* * *}, P=0.000$ respectively).

No correlations were reported between serum ceruloplasmin level and each of serum SOD, MDA, and CAT levels in group A (Table 2).

\section{Discussion}

Many studies stated that the pathogenesis of POAG is still under investigations, some known risk factors were incorporated in the process of POAG such as IOP, vascular supply for retinal nerve fiber layer, retinal ganglion cells degenerations and optic nerve protective mechanisms [1] [3]. Other contributing factors which were reported by authors as Majstereketai (2011) [14], Anholt and Carbone (2013) [4] and Mumcu et al. (2016) [13] were oxidative stress, inflammatory factors and characteristic pattern of cell death by apoptosis, the present study 
Table 2. Correlations between serum ceruloplasmin $(\mathrm{mg} / \mathrm{dl})$ levels and all studied parameters in all groups.

\begin{tabular}{cccc}
\hline Groups & $\begin{array}{c}\text { Group A } \\
\text { (Control) }\end{array}$ & $\begin{array}{c}\text { Group B } \\
\text { (Untreated POAG) }\end{array}$ & $\begin{array}{c}\text { Group C } \\
\text { (POAG under treatment) }\end{array}$ \\
\hline Serum SOD & $\mathrm{r}=0.283$ & $\mathrm{r}=-0.546^{* *}$ & $\mathrm{r}=-0.483^{\star *}$ \\
$(\mathrm{U} / \mathrm{ml})$ & $\mathrm{P}=0.129$ (IS) & $\mathrm{P}=0.002$ & $\mathrm{P}=0.007$ \\
Serum MDA & $\mathrm{r}=0.303$ & $\mathrm{r}=-0.680^{\star * *}$ & $\mathrm{r}=-0.557^{\star *}$ \\
$(\mathrm{nmol} / \mathrm{ml})$ & $\mathrm{P}=0.104$ (IS) & $\mathrm{P}=0.000$ & $\mathrm{P}=0.001$ \\
Serum CAT & $\mathrm{r}=0.144$ & $\mathrm{r}=0.596^{\star *}$ & $\mathrm{r}=0.796^{\star * *}$ \\
$(\mathrm{U} / \mathrm{ml})$ & $\mathrm{P}=0.449$ (IS) & $\mathrm{P}=0.001$ & $\mathrm{P}=0.000$ \\
\hline
\end{tabular}

IS $=$ insignificant; ${ }^{* *}=\mathrm{P}<0.01 ;{ }^{* *}=\mathrm{P}<0.001$.

evaluated these contributing factors in POAG before and during medical treatment.

The present study reported that serum ceruloplasmin was decreased significantly in both group B and C of untreated and treated POAG patients in comparison to the control group in agreement with the study of Sarnat-Kucharczyk et al. (2016) [10], who recorded the same results in POAG. However, other studies reported that ceruloplasmin was up regulated in murine and human retina Muller cells in response to retinal ganglion cells death denoting that ceruloplasmin may have a protective role in neurodegenerative conditions as POAG [16] [17]. So regular assessment of serum ceruloplasmin may be considered a high value in monitoring neurodegenerative process in POAG.

As regards to antioxidant status, the present study reported that serum catalase activity decreased significantly in both group B of untreated POAG patients and in group $\mathrm{C}$ of patients of POAG under treatment, when compared to the control group A.

This coincides with Majsterek et al. (2011) [14], who stated that antioxidant activity decreased in POAG aiming to find the possible way to increase this activity in management of such cases as the present study also reported that this activity was decreased even in patients under medical treatment by topical carbonic anhydrase inhibitor and non-selective B blocker. In controversy with our finding, Goyal et al. (2014) [18], found that there was no significant change in CAT activity in aqueous humor of POAG patients.

But, about serum superoxide dismutase, the present study reported that it increased significantly in group B of untreated POAG patients and also in group C of patients of POAG under treatment in comparison to the control group, in agreement with Erdurmuş et al. (2011) [11], who reported the same results, in addition Ghanem et al. (2010) [19], who found that superoxide dismutase increased significantly in aqueous humor in patient of POAG. But, Majsterek et al. (2011) [14], reported that SOD was decreased in patients with POAG as it is considered anti-oxidant factor, the present study and the previous two studies that agreed in their results of increase of SOD in patients of POAG explained this increase to be a compensatory mechanism for anti-oxidant activity against 
stress mechanisms in patients with POAG which was obvious in SOD rather than CAT activity.

In the present study, serum malondialdehyde increased significantly in group B of untreated POAG patients and in group C of patients of POAG under treatment ,which was in agreement with many studies such as Mumcu et al. (2016) [13] and Majsterek et al. (2011) [14], who stated that MDA increased in cases of POAG as an oxidative stress biomarker. Also, the present study reported that there were negative correlations between serum ceruloplasmin and SOD and MDA levels in patients with POAG and positive correlations between serum ceruloplasmin and CAT levels in patients with POAG.

\section{Conclusion}

In cases of POAG, serum ceruloplasmin and CAT activity decreased significantly and serum levels of SOD and MDA increased significantly. Monitoring of serum levels of ceruloplsmin, SOD, MDA and CAT activity may play an important role for determining of the oxidative stress condition of such cases. Aiming at adding the anti-oxidative therapy in conjunction to the anti-glaucomatous drugs (especially Dorzolamide-Timolol) in the management of cases of POAG. Other oxidative stress markers may be in need for further investigations and determination of its relations to different anti-glaucomatous drugs.

\section{Conflict of Interest}

The authors declare no conflict of interest

\section{References}

[1] Sena, D.F., Ramchand, K. and Lindsley, K. (2010) Neuroprotection for Treatment of Glaucoma in Adults. Cochrane Database of Systematic Reviews, 2, Article ID: CD006539. https://doi.org/10.1002/14651858.CD006539.pub2

[2] Neamatzadeh, H., Soleimanizad, R., Zare-Shehneh, M., et al. (2015) Association between p53 Codon 72 (Arg72Pro) Polymorphism and Primary Open-Angle Glaucoma in Iranian Patients. Iranian Biomedical Journal, 19, 51-56.

[3] Vohra, R., Tsai, J.C. and Kolko, M. (2013) The Role of Inflammation in the Pathogenesis of Glaucoma. Survey of Ophthalmology, 58, 311-320. https://doi.org/10.1016/j.survophthal.2012.08.010

[4] Anholt, R.R. and Carbone, M.A. (2013) A Molecular Mechanism for Glaucoma: Endoplasmic Reticulum Stress and the Unfolded Protein Response. Trends in Molecular Medicine, 19, 586-593. https://doi.org/10.1016/j.molmed.2013.06.005

[5] He, X., Hahn, P., Iacovelli, J., et al. (2007) Iron Homeostasis and Toxicity in Retinal Degeneration. Progress in Retinal and Eye Research, 26, 649-673. https://doi.org/10.1016/j.preteyeres.2007.07.004

[6] Osaki, S., Johnson, D.A. and Frieden, E. (1966) The Possible Significance of the Ferrous Oxidase Activity of Ceruloplasmin in Normal Human Serum. Journal of Biological Chemistry, 241, 2746-2751.

[7] Goldstein, I.M., Kaplan, H.B., Edelson, H.S. and Weissmann, G. (1982) Ceruloplasmin: An Acute Phase Reactant That Scavenges Oxygen-Derived Free Radicals. Annals of the New York Academy of Sciences, 389, 368-379. 
https://doi.org/10.1111/j.1749-6632.1982.tb22150.x

[8] Kuryshova, N.I., Vinetskaia, M.I., Erichev, V.P., et al. (1998) Permeability of Blood-Aqueous Humor Barrier in Primary Open-Angle Glaucoma. Vestnik Oftalmologii, 114, 10-13.

[9] Miyahara, T., Kikuchi, T., Akimoto, M., et al. (2003) Gene Microarray Analysis of Experimental Glaucomatous Retina from Cynomologous Monkey. Investigative Ophthalmology \& Visual Science, 44, 4347-4356.

https://doi.org/10.1167/iovs.02-1032

[10] Sarnat-Kucharczyk, M., Rokicki, W., Zalejska-Fiolka, J., Pojda-Wilczek, D. and Mrukwa-Kominek, E. (2016) Determination of Serum Ceruloplasmin Concentration in Patients with Primary Open Angle Glaucoma with Cataract and Patients with Cataract Only: A Pilot Study. Medical Science Monitor, 22, 1384-1388.

https://doi.org/10.12659/MSM.895352

[11] Erdurmuş, M., Yağc1, R., Atış, Ö., Karadağ, R., Akbaş, A. and Hepşen, I.F. (2011) Antioxidant Status and Oxidative Stress in Primary Open Angle Glaucoma and Pseudoexfoliative Glaucoma. Current Eye Research, 36, 713-718. https://doi.org/10.3109/02713683.2011.584370

[12] Rokicki, W., Zalejska-Fiolka, J., Pojda-Wilczek, D., Kabiesz, A. and Majewski, W. (2016) Oxidative Stress in the Red Blood Cells of Patients with Primary Open-Angle Glaucoma. Clinical Hemorheology and Microcirculation, 62, 369-378. https://doi.org/10.3233/CH-152029

[13] Mumcu, U.Y., Kocer, I., Ates, O. and Alp, H.H. (2016) Decreased Paraoxonase1 Activity and Increased Malondialdehyde and Oxidative DNA Damage Levels in Primary Open Angle Glaucoma. International Journal of Ophthalmology, 9, 1518-1520.

[14] Majsterek, I., Malinowska, K., Stanczyk, M., Kowalski, M., Blaszczyk, J., Kurowska, A.K., Kaminska, A., Szaflik, J. and Szaflik, J.P. (2011) Evaluation of Oxidative Stress Markers in Pathogenesis of Primary Open-Angle Glaucoma. Experimental and Molecular Pathology, 90, 231-237. https://doi.org/10.1016/j.yexmp.2011.01.001

[15] Awodele, O., Oreagba, I.A., Olayemi, S.O., Oladipo, I., Iruegbukpe, C.O., Balogun, B.G., Balogun, M.M. and Adedokun, A.O. (2015) Evaluation and Comparison of the Indices of Systemic Oxidative Stress among Black-Africans with Age-Related Cataracts or Primary Glaucoma. Middle East African Journal of Ophthalmology, 22, 489-494.

[16] Klomp, L.W., Farhangrazi, Z.S., Dugan, L.L. and Gitlin, J.D. (1996) Ceruloplasmin Gene Expression in the Murine Central Nervous System. Journal of Clinical Investigation, 98, 207-215. https://doi.org/10.1172/JCI118768

[17] Stasi, K., Nagel, D., Yang, X., et al. (2007) Ceruloplasmin Upregulation in Retina of Murine and Human Glaucomatous Eyes. Investigative Ophthalmology \& Visual Science, 48, 727-732. https://doi.org/10.1167/iovs.06-0497

[18] Goyal, A., Srivastava, A., Sihota, R. and Kaur, J. (2014) Evaluation of Oxidative Stress Markers in Aqueous Humor of Primary Open Angle Glaucoma and Primary Angle Closure Glaucoma Patients. Current Eye Research, 39, 823-829. https://doi.org/10.3109/02713683.2011.556299

[19] Ghanem, A.A., Arafa, L.F. and El-Baz, A. (2010) Oxidative Stress Markers in Patients with Primary Open Angle Glaucoma. Current Eye Research, 35, 295-301. https://doi.org/10.3109/02713680903548970 